\title{
Discussion on Information-Based Teaching Reform under the Background of Smart Education
}

\author{
Yanming Yang, Yinpeng Qi, Yumin Shi \\ Qingdao Campus \\ Naval Aviation University \\ Qingdao 266041, P. R. China
}

\begin{abstract}
With the deep integration of "Internet+" and education and the introduction of smart education, how to promote the reform of information technology teaching in colleges and universities and accelerate the cultivation of highquality talents has become a major issue facing college education in the new era. Smart education is an advanced stage of the development of educational informatization. It is based on the learning and development of all students. It uses the "Internet +" thinking and technology to create a smart learning environment, provide effective educational services for learners, and promote traditional teaching. Structural changes promote the individualized development of students. This paper explores the scientific connotation and basic characteristics of smart education, analyzes the problems existing in the current information-based teaching in colleges and universities, gives the basic principles that should be grasped in informatization teaching, and discusses the countermeasures of informationbased reform in detail.
\end{abstract}

Keywords-higher education; smart education; informationbased teaching; blend teaching; flipping classroom

\section{INTRODUCTION}

With the development and application of modern technology such as cloud computing, big data, mobile Internet, $\mathrm{AI}$, and so on, the penetration and integration of "Internet +" and education are deepening. The connotation, depth and quality of information-based teaching are constantly developing. The structure and form of education and teaching system are undergoing transformation and transformation, and gradually form new. The concept and mode of education is smart education. Intelligence education is the advanced stage of the development of educational informatization. It takes the learning and development of all students as the center and makes use of the thinking and technology of "Internet + " to create a learning environment with smart, providing intelligent and efficient educational services for learners, promoting the transformation of traditional teaching structure, and promoting the individualized growth of students.

\section{SCIENTIFIC CONNOTATION AND BASIC CHARACTERISTICS OF SMART EDUCATION}

\section{A. The Scientific Connotation of Smart Education}

Intelligent education refers to the integration of the Internet of Things, cloud computing, big data, mobile Internet, artificial intelligence, virtual reality and other new information technology tools with educational concepts and practices, the construction of networked, digital, intelligent learning space, learning ecology and modern education models and systems, aimed at promoting education stakeholders. Ability generation, individualized development, smart cultivation and sustainable development promote the innovation and reform of education [1][2].

\section{B. The Basic Characteristics of Smart Education}

The essence of intelligent education is to realize the sharing of educational information and knowledge by means of educational informatization. Smart education is firstly the deep integration of information technology, secondly the seamless integration of educational resources around the world, and finally the high degree of agreement between teaching and learning, and ultimately achieve the goal of smart education [3].

Deep integration of information technology. Intelligent education is the latest stage of the development of educational informatization. Its greatest feature is the application of advanced information technology such as mobile Internet, big data cloud computing and Internet of Things, and its integration with education [4].

Seamless integration of educational resources. The seamless integration and sharing of global high-quality educational resources is one of the main characteristics of intelligent education [5].

The combination of teaching and learning is highly consistent. The application of the new generation of information technology has made it possible to carry out a variety of teaching and learning methods, and teaching and learning from the perspective of intelligent education has also shown a new feature [6].

\section{MAIN PROBLEMS IN INFORMATION-BASED TEACHING}

At present, colleges and universities are facing many difficulties and problems in speeding up information teaching. Most of the higher education still stays at the stage of "teachercentered" traditional teaching occupying the main body. Although some courses introduce new teaching ideas, they have not completely broken the inherent mode of traditional teaching and realized fundamental changes. 
A. The Concept of Education is Relatively Backward, and the Research on New Teaching Models is Insufficient.

At present, the relative backwardness of educational concepts has become the key to restricting the development of information technology education in colleges and universities. Most teachers still feel that "preaching, teaching, and confusing" should be taught to the students by the basic knowledge, basic theories and principles of the subject. Students only need to listen carefully. The educational value of the Internet+ era is not only to let students remember concepts and rules, but also to cultivate students' ability to learn in depth, such as critical thinking, problem solving, and migration, to teach for the unknown, and to learn for the future. Facts have proved that the traditional "cramming" teaching mode has been detrimental to the formation of student problem solving and migration ability, and has restricted the development of students' self-learning ability.

\section{B. Insufficient Construction of Informatization Conditions} Restricts the Development of Informatization Education

The typical informatization teaching environment should be the cyberspace classroom environment. At present, most military academies still stay in the multimedia network classroom environment, and the construction of smart classrooms is in its infancy. Information technology means is the material basis of information-based teaching. The construction of information resources and the application of information technology means are conducive to the realization of educational informatization, which is conducive to giving play to students' main status and breaking through barriers between teachers and students. The essence of informatization teaching should be teaching. The basis of its support is technology. At present, there are still problems in the construction of informatization conditions in colleges and universities, which restricts the development of educational informatization.

\section{The Lack of Teachers' Information Awareness and the Urgent Need to Improve the Ability of Information-Based Teaching}

From the perspective of using information technology to reflect modern teaching ideas and concepts and optimizing teaching, many teachers still lack the ability of informationbased teaching design and implementation, lack of new educational concepts and methods in the context of information-based teaching, and lack of information-based teaching. Overall consideration. In addition, the phenomenon of "two skins" in information-based teaching still exists, and the enthusiasm for promoting education informatization needs to be improved, and the intensity needs to be increased. The institutional mechanism still needs innovation, and the application motivation of teachers and education administrators needs to be further stimulated. Cyber security awareness and protection capabilities need to be strengthened. The progress of informatization construction is not balanced, and the level of development of informational areas still has great differences. Faced with these difficulties and problems, we need to further raise our awareness, change our mindset, work together, and overcome difficulties.

\section{BASIC PRINCIPLES OF INFORMATION-BASED TEACHING}

\section{A. Quality Oriented, Educating Students ts the Foundation}

Following the teaching characteristics and laws of higher education, taking the cultivation of high-quality talents in the new era as the basic starting point and foothold of informationbased teaching, focusing on shaping professional quality, improving professional quality and promoting all-round development, scientifically constructing the information-based teaching environment, and striving to provide each student with personalized learning and lifelong learning Information environment and services.

\section{B. Application Driven, Co-Construction and Sharing}

Guided by the needs of personnel training, education reform and development, we should develop and apply highquality digital education resources, construct an informationbased learning and teaching environment, and establish an open and cooperative mechanism for University guidance, multi-party participation and sharing.

\section{Overall Planning and Classification Promotion}

According to the characteristics of various types of education in Colleges and universities, the overall planning and top-level design of education informatization should be well planned, the key points of development should be made clear, the classification guidance should be adhered to, and the characteristics should be encouraged.

\section{Deep Integration and Leading Innovation.}

To explore the comprehensive and deep integration of modern information technology and education and teaching, to lead the innovation of educational concepts and modes by informatization, and to give full play to the supporting and leading role of educational informatization in the reform and development of education and teaching [7].

\section{COUNTERMEASURES FOR THE REFORM OF INFORMATION-BASED TEACHING}

\section{A. Updating Teaching Concepts and Exploring New Modes of Blend Teaching}

In general, hybrid teaching refers to the combination of Online Learning and Face-to-Face Learning, which is a combination of online learning (online) and classroom learning (offline). Combination of. Hybrid teaching focuses on combining the advantages of traditional classroom teaching and online teaching, changing the roles of teachers and students, embodying the teaching philosophy of "taking students as the main body and teaching as the leader". Teachers are guiding, supporting, supervising and controlling. The role of students to make full use of the environment created by teachers, free and independent learning [8].

At the same time, blend teaching can make full use of various teaching resources, expand the knowledge of students, and also optimize the combination and rational use of various teaching methods, teaching media, teaching strategies, etc., to 
play the main role of students and cultivate students' enthusiasm. And creativity.

The essence of informatization is teaching reform, not technological innovation. In the final analysis, information technology is to serve the content of teaching, in order to improve the quality of classroom teaching. The application of information-based teaching methods is important, but it must not be "informatized for informatization." Therefore, if the teaching reform is to succeed, it must be supported by advanced teaching concepts. In the process of teaching, the curriculum team explores the hybrid teaching mode, which is also the "face-to-face + online" model. This model is also more conducive to the formation of students' learning ability and migration ability, and has achieved good results.

Many courses can be carried out in a blend teaching mode, such as a software practical class, which can be a blend teaching mode. If you put the simple operation steps under the class, let the students use the network resources to self-learn, the teachers prepare the class materials according to the students' self-study conditions, and the students find their own problems after self-study, so that they can bring questions into the classroom, the classroom Limited time is used to solve the difficulties of students. That is to say, by flipping the timing of resource provision, the realization of prior cognition is induced. With the rich resources in the network platform, students can enter the learning state in advance, enter the classroom with problems, and the desire to solve will occur. The teaching and learning can be more effective. Through the teacher guidance in the classroom, students free speech, group discussion, group debate and other forms to flip the time of questioning, inspiring students to understand in the inquiry, is conducive to the formation of students' ability to move.

\section{B. Optimizing Teaching Design and Promoting Deep Integration of Information Technology and Classroom Teaching}

The rationality and excellence of teaching design directly affect the teaching effect of classroom teaching and the realization of teaching objectives. Adopting the hybrid teaching mode is to break the traditional teaching design ideas, carefully design three teaching links before, during and after the class, reduce the time for the teachers to concentrate, and use the reasonable design to give full play to the students' dominant position in a limited class. Improve teaching efficiency and promote the transition of students from passive learning mode to active learning mode.

If the hybrid teaching mode is applied, the teaching organization and implementation in the cyberspace classroom environment, combined with the whole process evaluation, through the pre-class self-study, classroom teaching, afterschool development, three teaching links to carry out teaching activities, highlighting the student's subjective position, Strengthening the formation of students' skills will effectively improve teaching efficiency.

Pre-class teaching. Open the network laboratory to the students. The students can review the pre-study tasks through the online course, use the teaching micro-videos in the online course, teach the teaching materials, teach the courseware and other resources, learn the operation process autonomously, and submit the screen recording of the operation process.

Classroom teaching. According to the teaching objectives, the questionnaires are used to collect the students' difficult points, and then the actual tasks of the troops are selected as drivers. In the process of completing the tasks, using information technology, adopting "teacher guidance, free speech, group discussion, group debate”, etc. The method breaks through the difficulty of teaching. Then carry out the post to do the work and test the learning effect.

After-class teaching. The students complete the rotation expansion task on the online course platform and submit the screen video. The teacher makes an evaluation based on the automatically collected video recording and the screen video submitted by the student, and promptly responds to the student's questions and answers questions. The application of the whole process evaluation management system to carry out diversified evaluation of the whole process, to achieve diversification of evaluation subjects and diversification of evaluation methods, is conducive to the comprehensive and accurate grasp of teaching effects by both teaching and learning.

\section{Integrating Information Resources and Improving Informatization Teaching Conditions}

Informatization teaching is inseparable from the application of information technology, the condition is the material basis of information-based teaching. The application of information technology includes the construction of information resources and the use of information technology. To implement the hybrid teaching model, it is necessary to construct the information resources required for the course, ensure the students' offline learning effect, highlight the functional positioning of the resource library "can learn and supplement the teaching”, and develop virtual simulation training based on the military post environment and work process. Resources and personalized autonomous learning systems lay the foundation for blend teaching implementation.

The hybrid teaching model needs to ensure the students' offline learning effect, which requires advanced information technology to set up high-quality information resources. If you want to introduce information technology, you need to understand what advanced local information technology is. You can participate in various information technology promotion conferences held inside and outside the military, extensively explore and study the characteristics of information technology, and analyze the advantages and disadvantages of various technologies. Then, according to the achievement of the teaching objectives, select appropriate teaching methods and methods to integrate information resources to meet the needs of "offline” learning.

In order to improve the efficiency of classroom teaching, a variety of information-based teaching methods can be comprehensively applied in the classroom teaching process to effectively help students achieve their learning goals. For example, the e-bag classroom management system and the multimedia teaching management software can be applied as the core of the classroom management; the dual touch screen can be applied as a display means, and the teaching function of 
the display screen can be flexibly adjusted according to the needs of different teaching scenes, thereby realizing various dual-screen application modes, and effectively Improve the efficiency of learning and training.

\section{Giving Play to the Role of Team and Promoting Connotative Sustainable Development of Informatization Teaching}

Team building is the basic guarantee for the development of educational informatization. In the course of curriculum construction, we must pay attention to the strength of the team and related organizations. For example, the agency funds to carry out teaching aids and animation production, and the teaching supervision experts have repeatedly reviewed and guided, and determined the idea of organizing implementation around the teaching objectives, and the means should be content services. In the classroom teaching, new ideas were introduced, new methods were applied, and new methods were adopted. The course team conducted collective research, trials and lectures, and repeated polishing to ensure the teaching effect. In the construction of resources, give full play to the professional expertise of team members, research and develop the whole process evaluation software, and provide guarantee for the implementation of blend teaching. The whole process of course construction is also the in-depth understanding of the content of informatization teaching by members of the course team, effectively driving information-based teaching in our school. The result of the landing and the promotion of the connotative sustainable development of information-based teaching [9].

\section{E. Taking the Construction of Smart Classrooms as a Breakthrough to Enhance Teaching Conditions of Smart Education}

Smart education advocates the use of the power of information technology to create a time-space environment with certain smart, which is a new realm and new appeal of contemporary educational informatization. Smart classroom is a new type of classroom that optimizes the presentation of teaching content, facilitates the acquisition of learning resources, promotes classroom interaction and individualized teaching activities, and has contextual awareness and environmental management functions. Generally, smart classrooms need to meet the following basic requirements: flexible space layout, seats can be adjusted at will to facilitate space segmentation; multiple handheld computer terminals interconnected; multi-angle projection or blackboard; convenient and fast Internet information retrieval for all individuals, analysis, and presentation of services [10].

Smart classrooms provide an interactive and efficient learning environment for teaching and learning, making it possible to share, explore, produce and apply knowledge in the classroom, providing environmental guarantees for cultivating innovative talents, and providing data for teaching processes and teaching decisions. support. To this end, how to carry out the teaching design of knowledge construction according to the characteristics of domestic smart classroom teaching, collect the data in the process of learner knowledge construction, analyze the learner's collaborative knowledge construction behavior and knowledge construction process, and timely and effectively feedback the knowledge construction effect is still very Big room for improvement.

\section{CONCLUSION}

In summary, the construction of educational informatization is an important breakthrough in realizing the modernization of college education. The construction of educational informatization is a long-term and complicated system engineering. There are many problems to be solved at present, and it is impossible to accomplish it overnight. All institutions must start from the leadership to lead their own personnel, emancipate their minds, update their concepts, fully recognize the importance of education informatization in military academies, and actively and scientifically solve the existing problems. The front-line staff must change their educational concepts, update their educational models and teaching content, improve teaching methods and methods, and promote major changes in teaching models, learning methods, management procedures, etc., thus accelerating the pace of deepening reform and overall advancement, and cultivating more for the country. More and better talents to adapt to the needs of information construction.

\section{REFERENCES}

[1] Uskov, Vladimir L., R. J. Howlett, and L. C. Jain. Smart Education and e-Learning 2016. Springer International Publishing, 2016.

[2] Versteijlen, Marieke, P. P. Salgado, and M. J. Groesbeek. "Smart Education." ICT for Sustainability 2016.

[3] Zhu, Zhi Ting, M. H. Yu, and P. Riezebos. "A research framework of smart education." Smart Learning Environments 3.1(2016):4.

[4] Wu, Wenjun. "Learning Analytics for Smart Education." e-Education Research (2017).

[5] Jing, Guoping, S. O. Education, and H. University. "Education Wisdom Ethics:A New Realm of the Teachers' Professional Ethics." Journal of Shanghai Normal University (2015).

[6] Hu, Qintai, et al. "Research on the Systematical Technology Analysis and Integration Path of Smart Education." China Educational Technology (2016).

[7] Visvizi, Anna, M. Lytras, and L. Daniela. (Re) Defining Smart Education: Towards Dynamic Education and Information Systems for Innovation Networks. Enhancing Knowledge Discovery and Innovation in the Digital Era. 2018.

[8] Zhao, Yan Na. "Research and Practice on Blend Teaching of Organic (SPOC) + Flipped Class." Guangzhou Chemical Industry (2018).

[9] Zhang, Xiu Yan, and X. N. Luo. "Research on the Construction of Information-based Teaching Mode Aiming at "Autonomous Learning"." Education Teaching Forum (2018).

[10] Yan, L. I., and Y. Gao. "Development of Information-based Teaching Ability of Teachers based on International Perspective." Journal of Tianjin Vocational Institutes (2018). 